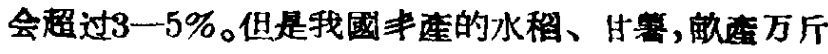
至数万斤，光能利用率已达到了 $20 \%$ 或更高。同时， 叶是作物吸收光能的器官, 过去認为叶的总面積在一 定限度內与作物量成正比，但叶面皘增加到一定程 度时，師叶面積和土地面積的比例达到 $4: 1$ 时，度量

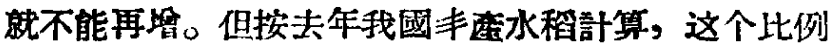
数已达到10:1，20:1，40:1，或者更多，作物度量却 並未受叶面積的限制而停止增長。另外，去年農業丰 的異乎尋常的高額原量的情况还表明，高等称色 植物除了利用光能制造有机物質以外，还有可能直接 吸收有机物賀。

\section{八、改变了对植物習性的陈旧覌点，充分 挥了作物的無限生产㴗力}

过去对作物品种的选育注意得多些，常常因此忽 視了人类栽培的重大意义。而丰的事实打破了有关 植物生長的环境决定論、条件論等,充分說明了植物的 晳性可因栽唔措施的改变而發生巨大的变化。过去認 为是栈根系的植物，事实証明只是因为淺铁限制了它 的根系發有。过去视为作物谷粒于焦只佔植物干重的
三分之一大右，但是根括我國丰水程計算，谷粒的 干重約为全部植物干重的一牛或者更多。过去一向铅

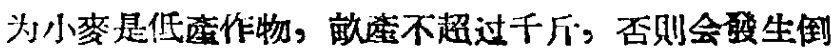

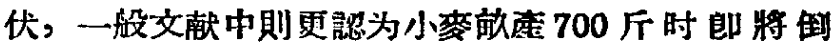
伏。但是在深耕、密植、多肥条件之下，小麥的最高 畧达到了七千斤、八千斤之多，也没有㡎生倒伏。 过去不少人在陈旧的理論基礎上淮行缉因子試驗，得 出了錯器的結諭，認为媱植会使作物穗小、程軟、粒少、 易倒，而实际上在丰裳田中，小麦每的可有140-150万 穗，水稻每喃多至10万范以上，並洺有造成穂小、粒 少，也没有倒伏。相反地，在密植的基礎上还創造了 以主穗为主的高度密植的理論和增加播种量、縮小行 距、交义播种、均匀撒播等召体措施。过去有人認为 棉花笛鉿的䏩落是不可避凂的，棉株之所以多着生果 節，就是为了防备脫澿，但是实际上，我國去年大踓

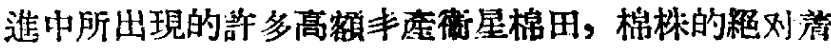
鉿率大大的增加，說明了防止棉花鳌鈴的脽浮是完全

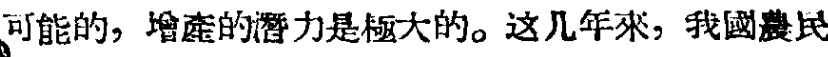
还利用雜交的方法，創造出了䄼大、粒肥、程粗、高 窟的許多优良的作物品种。

\title{
帶电粒子加速器的种类特性和用途
}

\section{桂 偉 䙪}

\section{一 总 論}

（一）加速器应用的一般介紹

“帶电粒子加速器”是朾人工方法使染电粒子受电 磁㘯作胢而加速达高能量的裝置，一般简称为 “扣速 器”,其用途很广:

1. 首先在原于核物理领域, 常要求从㧈速器中

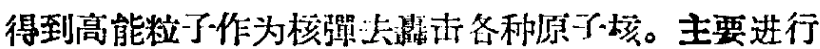
的工作有以下三方面。

(1) 核反应工作;

(2) 核結權問題的研究;

(3) 核力問題的研究。

通常作为核翼的粒子有五种: $\alpha\left(\right.$ 氮核 $\left.{ }_{2} \mathrm{He}^{4}\right), d$

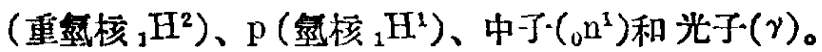
后网种核彈不帶电, 虽不能直接由加速器获得, 但可 以通过㧝电粒子的核反应問接地得到。侧如分核与氛 核作朋故出中子，电子射綫遇到其他物質則放出 $\gamma$ 射 綫等等。

用加速器供給的核彈进行核反应工作，比起天然 放射物来有无可疽疑的优越性: 一是佨彈种类多，二 是能量高，三是强度大，四是火力集中。
天然放射物放出的射程一般有三种。一种是 $\alpha$ 射 种射綫)，一种是 $\beta$ 射綫(乙种射綫)，男一种是 $\gamma$ 射綫 (两种射綫)。其中 $\beta$ 射綫所包含的电子因和原

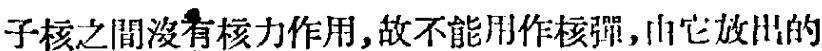
$\gamma$ 射䋐地区能量太低，很难引起核反应，而川小火然放 射之 $\alpha$ 粒子当作核彈, 效果他是很差的。因为 $\alpha$ 粒子 带有正电，在射古过程中沿途使其他原子产生电离， 因而西要消耗能量。而要想的入原子核，还必須范服北

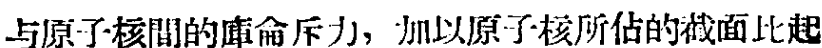
原子来只有一万万分之一，要想一次击中本来就不容 易, 因此对于能量不大的天然 $\alpha$ 射綫 (銛 $\mathrm{C}^{\prime}$ 放川1之文 $\alpha$ 只有五百多万电子·伏能量), 完成这項任务是很林难 的。盧瑟福在他第一次出鐇 $\mathrm{C}^{\prime}$ 放H $\mathrm{H}$ 的 $\alpha$ 粒子·进行的 核反应实驗中，发現四十一个 $\alpha$ 核强队只有八个起了 核反应就是这个道理。

而人工加速的粒子，由于能量可以很高，命中棟 也就大为增軠。目前世界上最大的苏联的質子同戈加 速器可以加速質子能量达到 100 亿电子伏( $10^{4} \mathrm{Mev}$ 牫 10Bev)。

另一方面，人工加速获得的粒了“流强度之大世远 非天然放射綫所能比捯。一克鋏在一秒之內向烦面八 
方放射出的 $\alpha$ 粒子总数为 $3.7 \times 10^{10}$ 个，相当于粒了 流强度为:

$$
\begin{aligned}
\left(3.7 \times 10^{10}\right) \times 2 \times\left(4.8 \times 10^{-10}\right) & \text { 静电單位 } \\
& =35.6 \text { 㙃电單位 } \\
& =0.012 \text { 微安 }
\end{aligned}
$$

而由一般回旋加速器就已經可以获得几百微安数量級 的粒子流, 相当于几十万克銚在各个方向放射性强度 的总和。自然, 用加速器射出的粒子流来作为核彈, 定將显示无比强大的威力。因此㧈速 器被为“向原 子核进軍中的必不可少的重要武器”。

2. 在机械工莱領域, 可以用加速器中得到的 $\gamma$ 射總进行探伤。

3. 冶金、塑料及其他領域也可以用 $\gamma$ 射結来照 射, 以求改良材料的机械、酎溫或絕練等各方面的性: 能。如鋼材受照射后可以提高机械强度，热望高分子 化合物䌽乙烯受輻射后, 耐 热性 可由 $70^{\circ} \mathrm{C}$ 提高到 $190^{\circ} \mathrm{C}$ 。这些都是很有发展前途的。

4. 医学上以加速器作为各种射線 $(n, p, \beta, \gamma$ 等), 来治疗毒秥或对生物进行射䋐病的研究。

5. 农粱方面, 射綫照射的应用更为广泛:

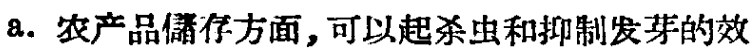
用: 如大谷仓受 $5,000-10,000$ 倫的 $\gamma$ 射䋊照射后， 可以將鼻虫部杀死。有的害虫藏在种子內部, 为 一般葋力所不及，但应用射挠則可得到显著效柴。馬 鍮薯受 5,000-20,000 偷的剂量后，則叮以保传几个 月不发芽变質, 新鮮如故。

b. 佱造新品种: 燕麦受中子流照射后，行得到 具有抵抗程銹病能力的新品种。

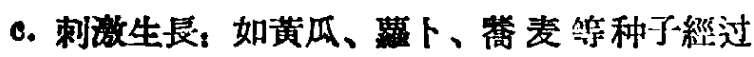
适度的 $\gamma$ 射䋐照射，下种后发芽又快又好，对增产很 有价做。

6. 食品工莱以 $\gamma$ 射綫来消毒，可以保持食物的 新鮮程度和营券价值。

如此等等, 不胜列举。

加速器所产生的射綫强度大, 用以进行各种工 作, 不但效率比較高, 而且具有很多的独特优点。这 在以后檴迌具体的加速器时, 还要提到。

\section{（二）加速器的种类}

到目前为止，世界上曾䅔有过的加速器形形色色 已不下数十种。其中有的已被淘汰，有的还不够成 熟。就拿基本上已被定了型的、被广泛朵用的来馀, 也有十余种之多。我們可以用不闰的原則加以分类。 例如有人从被加速粒子的种类估发，把它們分成: (1) 專門加速电子、(2)專門加速离子 $(\alpha, d, p)$ 和 (3) 订 加速任意一种帶电粒子等三大类加速器。也有人从粒 子运动仇道形式的角度着眼, 归羭成: (1)直綫軌道、 (2)䦎合圆軌道和(3)回旋式軌道三类川速器。

我們这里則从加速电磁坋的不同特点恬发, 把它
們分成四大类:

（1）静电㘯加速的高压加速器一一聿极加速 器 $\Delta \star$, 静电加速器 $\Delta \star$ 。

(2) 渦旋电㘯㞦速的感应加速器一一电了感应加 速器 $\Delta$.

（3）高頻（或微波）电坊旋轉軌道型共振版速

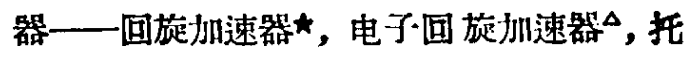

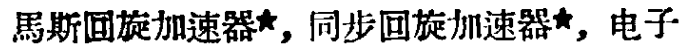
同步加速器 $\star$, 筫子同步扠速器 $\star$, 强聚焦同 步加速器 $\Delta$.

（4）微波电㘯加速器的直綫加速器一一电子行波

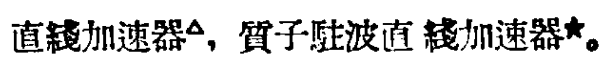

其中符是 $\triangle$ 是表示加速电子的， 大是表示加速离 于的.

不同的加速器虽各具有特点, 但大体都具备以下 三个主要部分:

（1）产生圌电粒子的机橉, 这就是所謂电子枪或 离子源。电子枪是在真空狀态下工作的，应用高溫阴 极的热发射或高电强的坊玫发射原理来获得电子，帮 由阳极电压的电坊作用將电子束射仙电子枪, 谁备加 速。离子源中则經常克以气体(其种类由加速 离子种 类决定)，它是应用热游离或高频游离的方法造成大 量离子, 再以附加电㘯將离子没出子源, 引到加速 軌道上去。

(2) 加速器的主体部分: 这部分的主要任务是保

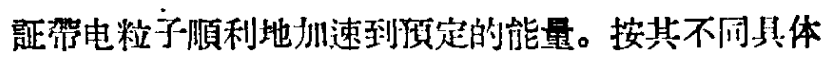
任务又可胴細分为三个系統:

a. 扣速电㘯柔統(包括它的电极和电源): 产生 电㘯使粒子小㧈速。

b. 控泚磁㘯系統(包括它的磁极和电源)：产生 磁㘯力使粒了限制在頋定的空閒》运动。

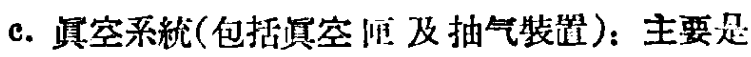
保証粒子在运动过程中, 侭可能避免与气体分子碰撞 而造成不必要的影响和損失。愐空度殌常总得在 $10^{-5}$ 铙米录杜以上。

(3) 粒子流引出机構: 主要任务是使加速后的粒 子通过附加的电㘯或磁㘯, 偏离其原有的軌道, 按项 䇥的方向引离加速器而加以应月。

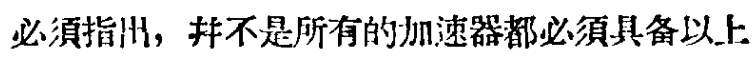
公个部分, 譬如直綫式帎道的玑速器就不必要控制磁 㘯, 它一㞦速器往往不要求引怕电子流, 就不必要第 (3)蔀分了。

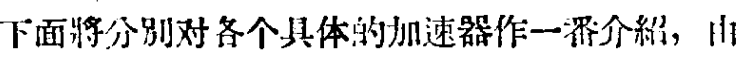

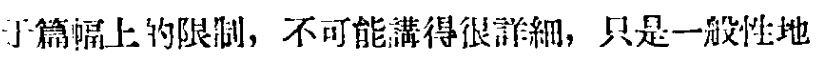
論述它們各个不闰的加速原理、特点和月途。陌对俚 級、静吨和感应三种川速器则稍为着重地满一滥, 闪 为这三种覑速器无渝从需要的数量或从技术条件来 看, 都宜㳀动票众广泛建造, 多快好省地全面推 
厂。至于其他类型的大加速器, 就全国范圍来講, 当 然也会有地方重点建造, 我們应革彻提高和普及相結 合、重点和全面相結合的方針，发动翠众来搞原子 能。

\section{二 串級高压加速器 (图 1) (高压倍增州速器)}

这是最早用来加速粒子的加速器, 其加速原理非 常簡單。当我們設法將高电压加在电极球売（一般用 鋁打成的）上, 則电极对地就有电㘯, 利用这个电㘯 力的作用, 帶电粒子就自离子源的口向接地的靶子方 向加速。图上我們見到若干中門加速电极。它們的作 用, 一方面是使电㘯均匀分布在各个电极綘間, 避龟 局部电㘯集中而引起电击現像; 另一方面, 这样所造 成的电极間一定形式的电㘯分布, 可使粒子流象通过 光学透鏡一样获得聚焦。

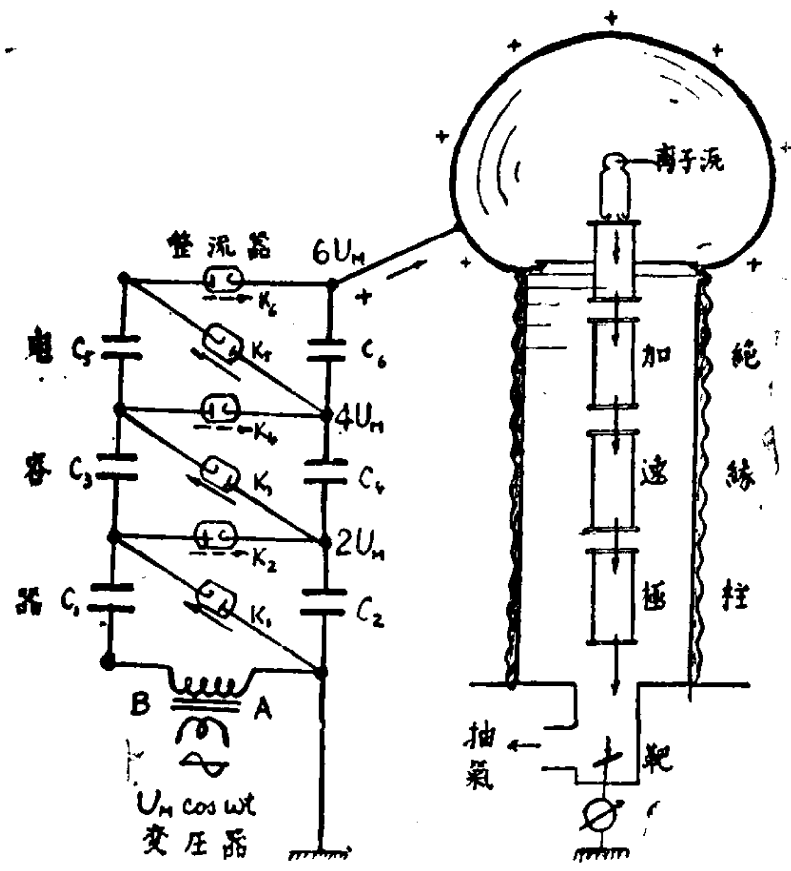

图 1

高压的产生是利用一套由电容器、整流器和一个 电源变压器組成的串級充放电綫路来获得的。图示共 有三层, 称为三級串联高压发生器, 其工作原理为: 利用整流器的單向导电特性, 当变压器 $A$ 端电位比 $B$ 高时, 整流器 $K_{1}$ 接通, 电源向电容器 $C_{1}$ 充电; 过 牛周期后, $B$ 端电位比 $A$ 高 时, $K_{2}$ 接 通, $C_{1}$ 向 $C_{2}$ 充电; 再以后牛周, $C_{2}$ 又向 $C_{3}$ 充电……这样当电 源电压不断反复交变 (一般为 50 周波), 勋整流器也就 交替地接通, 电荷就不断往上充, 当电源电压峯值为 $U m$, 則 $C_{1}$ 最高电压也可立达 $U m, C_{2}$ 是由 $C_{1}$ 及 电源串联着充电的, 故其最高电压河以达 $2 U m$ 。既 然右边电容上每一級可以得到 $2 U m$, 則三 級就可以 获得 $6 U \mathrm{~m}$ ，也郎是六倍于电 源电压。

这种加速器加速能量一般在一百万电子伏( $1 \mathrm{Mev}$
左右，也就是說其电极电压在一百万伏后右。电压值 提高主要受电容器和整流器耐压强度的限制。

由于不断地进行着充放电, 何:个电容器上的电荷 也就不断进师地流动, 这样就引起电压的波动。計算

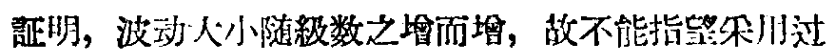
多的串級数来达到利高电压的目的。这种波动幅度比 起总电压来一般約相当于 $1 \%$ 左右，朵用較高的电源 频率可以减小这种电压波动。

建造串級州速器主要为商压技术問題, 一般困难 不算大。它的缺点在于-加速粒子能量軕低，日因电压 波动引起能量的不稳定，不宜位接把被井速的粒子用 作核反应工作。但以其粒了流大(几百微安)，常用被 加速的氛核路击公核产生大量中子，故被視为一很好 的中一源。很多中子物理工作, 可以在这里进行, 某 种程度上代替了反应堆工作。因此建造串䋆㧈速器的 意义不能拟以低估。由于每:个高压整流管都处在不同 級的高压下工作，故其灯綵电源必須对地絕緣，互相 分开。可尔肞單独的发电机供电，或級联式紹線变压 器供电。較先进的是采用特殊綫路的高頻加热。当然 若能箖用牛导体整流就沟有这类阔題, 但要求每一个 牛导体整流器都能耐几十万伏的高 压, 技术上很困 难, 是一个努力方向。

\section{三 㬹电高压加速器 (图 2) （范德格拉夫）}

靜电高压州速器的加速原理和前一种相同。差別 在于获得高压的方法不同。这里产生高压的裝置叫做 范德格拉夫静电起电机, 原理很简單。我們知道, 对 于一个金屬球壳, 电少只能稳定分布在外表面, 电荷 积聚越多, 球对地的电位就越高。电荷由一排与高 压电源相联的針尖 $A$ 的电最败电来供給。我們尔用

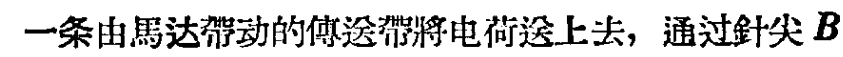
流到球上。这样, 电荷不断往上秐, 球的电位就越来 越高。与此同时, 球表面放电也越来越证。当放电电 荷能量和帶子一补充的电荷量相管的时节, 电压就不胡升高而达到作衡了。

靜电加速器能量最大可以达到 $10 \mathrm{Mev}$ 左右, 此 时球徑超过 4 米, 高度十几米。其珢大的特点就是結 構簡單, 粒子流强, 能量稳定度语达万分之一, 适宅 于作最精密的物理实驗, 为其他扒速器䜣不及。

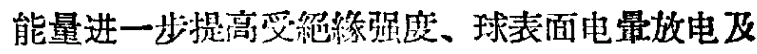
加速极冷放电等限啡。一味为人球徑, 增加高度, 不 見得有很大效果，也不經济; 因此設法朵取更有效的 均压措施(沿紹緗林用均压环)和策用高气压密閉式結

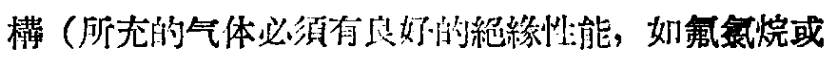
$\mathrm{N}_{2}$ 和 $\mathrm{CO}_{2}$ 的混会气体), 以墦强气体介質酎压, 加速电 极的形狀的改率也將有很大意义。

靜电加速器发展的一个重要方向, 是朵用负离子 
䃇和变极㥩海片。这 种加速器具有二个聿 联瓶的加速管，二端 接地，中關有漓压 球。会息子自一端向 隔压极方向加速, 至 商压端时声 打在变 极性海片的一个湎 上, 其另一面垖射仙 正离子，正离子受电 㘯作用，向箐另一个 撄地端又进行一次加 速。这样，以同样大 小的高电压就可收双 倍的加速效果。这种 㧈速器除高压問題 外，技术上的困难在 于负离子源和变极性: 消的制造。君来这是

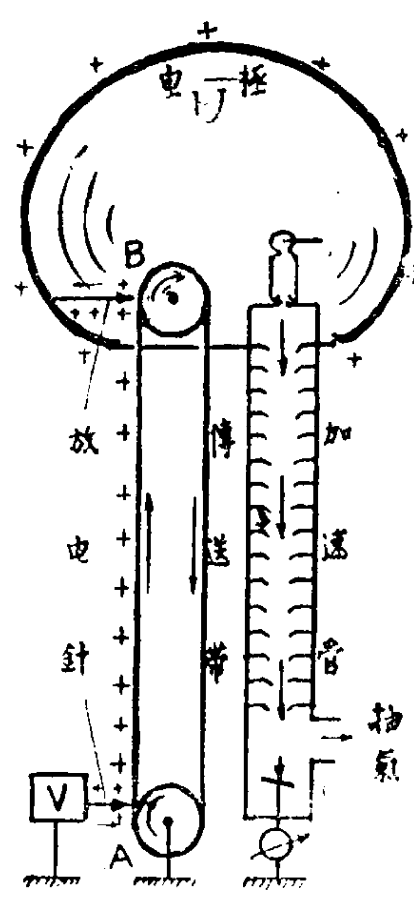

图 2 很有希㗨的一个方向。

\section{四电子感应加速器 (图 3)}

構造大致如图所示。磁极間之环形㣀空念郎为电 子运动的㘯所，帎道为一个閉合圆，处于盒当中。当 仇道所包司的中心磁㘯㙁大时，軌道上就产生感应电 势, 使射入的电子得到加速。由于俚道磁坊的存将， 运动軌道是目形的。在加速过程中离心力折人，电子： 介图扩大其运动牛徑，这时假如能相应地增大悓道矿 坊(加大磁㘯对电子的问心力作湖)，就可以維持电个 在一个不变的平衡沋道上加速。这就要求中心磁㘯和

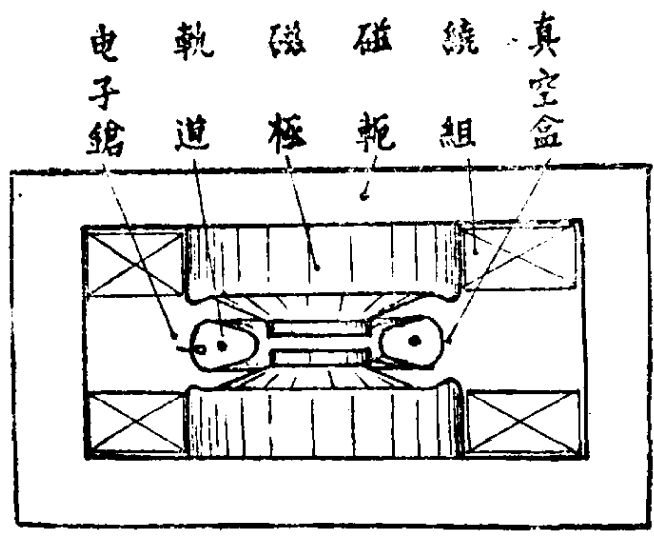

国 8

虬道磁培之間必須按一定比例分布，抹且同时改变。

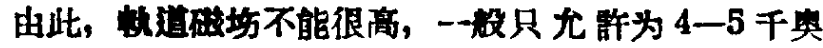

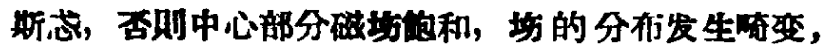

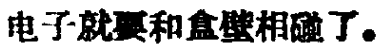

目前利用电子加速器，最高可以得到 $300 \mathrm{Mev}$ 的 电子, 此时輻射提失已极显蓄，約 $700 \mathrm{ev} /$ 圈(一般电 子白感应电坊中悔國获得的能量也不过几百伏到一千
(犬石右)，帎道就不再不变，能量进一步提高受到限制。

电子加速器常常可以作为强 $\gamma$ 源来应用, 其应州

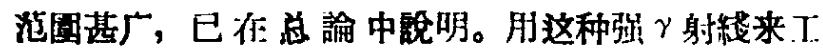
作，具有培多独特的优点。以金屡探伤为例，可以上 故射性同位素射綪及超声波管探伤作一此較。

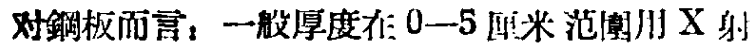
綫为宜，0-10 厘米汇圍可肞同位素如鈷 60，5-50 㕅米用电子小速器比较好，50厘米以上可用超声波。

可見用电子加速器或超声波都能对厚銅板进行探 伤。但是用超声波探伤有很多缺点。

（1）不能探出伤的哏跡，只能得到胙冲信量，以 后避免同样部位伤经的发生就很困难。

（2）常有錯誤信奇。

（3）探伤前要求將表面研磨好，費工很人，邚颌 件本来已坏, 则人力上泿費很大。

（4）对表面部分存不灵钻点。

(5) 不能对焊緹探伤，因此处山不同物筫組成， 密度不均匀。

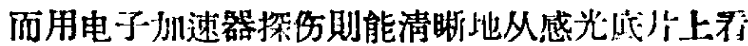
川裂䋐的哏跡，没有超声波这些缺点。与闰位添或 入

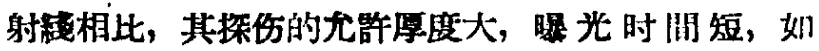
15 厘米的銀件用 500 克鐇当量的鋴 60 需 然五天，而 川 $25 \mathrm{Mev}$ 的电子加速器只要几分 鐘 就行了。它的射 綫强度的相当于 3,000 克錦当量, 可以发現小至道行 为 1.5 毫米的伤点, 为其他射綫所不及。

制造这种加速器主要的闲难在于矽鋼片組成的磁 极和环形真空回等的加工。但月前国內已經冾几个地 方突破这些困难, 谺制成功了。这說明只要放手发动 众，任何困难都是可以克服的。制造加速器持不斺 祕，大家都可以搞。

\section{五 电子同步加速器 (图 4)}

5 我們已經談到了电子加速器是点感应电㘯来川速

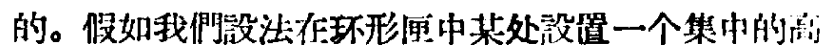
頻电㘯代替惑应电㘯加速，这就可以將中心部分磁通

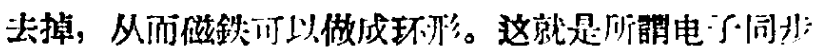
加速器。

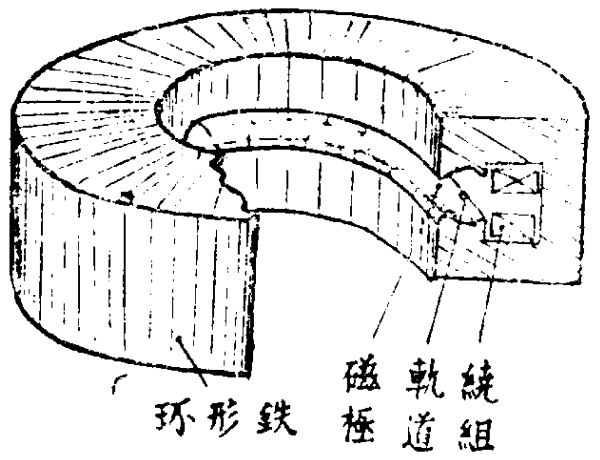

用 4 
电子同步加速器的特点是籸道磁坊和感应加速谷 一样需要随时增大, 而高頻頻率 $f$ 不改变, 也就是說 角頻 $w=2 \pi f$ 是常数, 可見运动牛徑 $r$ 將正比于䋨速 度 $v$ 而改变。但因为电子質量小，很快就趋近于光速 而以等速狀态运动, $v \doteq c=$ 常数, 故牛徑 $r$ 也就近似 地为恒定不变。可以看出, 环狀的軌道形式基本上还 能保持。这类少速器, 目前最大能量为 $500 \mathrm{Mev}$, 鉄 重近 300 吨。合理的能量极限值限定在 $10^{8} \mathrm{Mev}$ 氾圍 以內, 能量的侢进一步的提高, 受輻射損失及造价的 限制。

\section{六 翼子同步加速器}

（同步稳相必速器）

和电子同步加速器相似，但因質子在加速过程， 速度逐步的增長着，不如电子那么易于趋近光速。 由 $w=\frac{v}{r}$ 可以看H!, 要想使軌道依然保持环狀, 必須

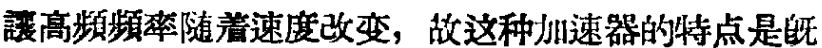
調磁㘯又調頻率, 丽者必須协調好于能保証軌道不改 变。最大能量为 $10^{4} \mathrm{Mev}$, 鉄重 36,000 蚰。能量进一 步提高受經济条件的限制。

\section{七 强琭焦同步加速器}

和一般同步加速器不同的只在于环形磁鉄分为一 节一节, 其中牛数磁㘯随牛仾方向增大，具一牛磁㘯 随坐徑的方向煘少，它們交替地排成环狀，一节与一 节間有楔彇綎。这样組成的磁坊有强聚焦作用，故环 形厘和仇道磁鉄可以做得更狭窄，省下大量鉄料，造 价大大降低。这样地就有可能允憵去造更大能量的加 速器。目前苏联已設計好的質子同步加速器能是为 $5 \cdot 10^{4} \mathrm{Mev}$, 鉄重 17,000 吨。能量进一步提高受經济 条件的限制。

\section{八 的旋加速器(图 5 a )}

一切回族扠速器的共同特点是, 它們都具有稳定 不变的磁坊，而且都应为高頻(或微波)电坊务次加速 原理来使帶电粒了获得能量。随着能量增長, 离心力 川大，运动牛徑也就增大，故軌道是螺旋式的。

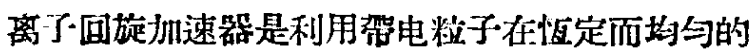
磁㘯中运动时角頻不变的原理（当資量相对性垥 長还 不显著时)，选摆高頻电㘯頻 率与之相等，这样离子 就有可能和电㘯取得同步, 如此能量就不断增加。但 由于能量大到一定程度时, 質量的相对性 增大显著 了，粒子回旋角頻就慢下来，和高频电㘯忩来忿失却 同歩，故加速能量受到限制。日前最大的可以得到筫 子能墨为 $24 \mathrm{MeV}$ ，磁鉄的重量侣: 400 吨以上。用回 旋加速器可以制造超鈾同位菜，这在反应陫上是作不 到的.

\section{九 同回莫加速器 \\ （相加速器）}

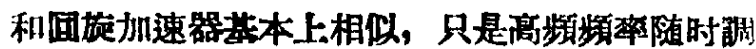
节使与加速器粒子同步，这样就可在質量相对性增人 的情况下笑行同频加速, 故能量此普通 回旋加速器 禹, 可加速离子 达 $10^{4} \mathrm{Mev}(10 \mathrm{Bev})$ 的能量积。目前 最大的一个订以加速页子达 $685 \mathrm{Mev}$ ，鉄重 7,000 炚。

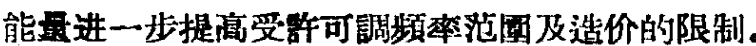

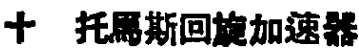

它与首通回旋加速器的差别，在于其磁极形狀治 幅角方向成波浪形，磁㘯梯度是交变的，因而造成了

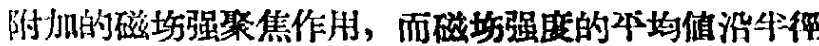
方向是具有增長特性的。故当离子能㙁大时，所处 的磁坋强度也大，可以保持离子的角频不变，从而使 采用不調頻的商頻电坊共振加速达到更高能量成为可 能。頖訫这种加速器强度較大, 能量可达 $800 \mathrm{Mev}$ 范 图。困难主要在于磁极面的精确設計和加工。

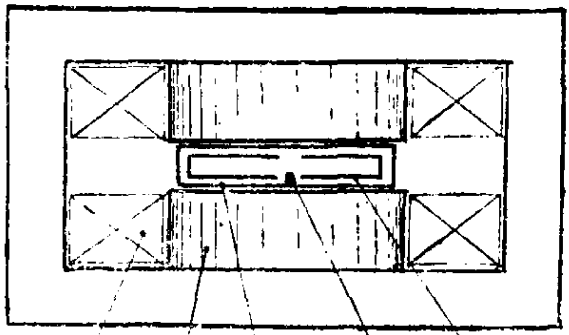

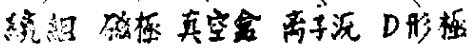

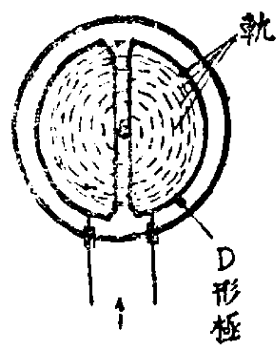

部频

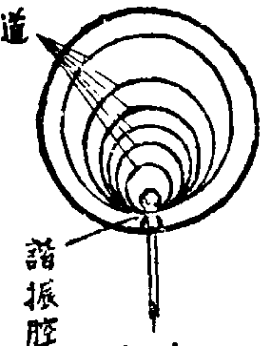

没洨
国

\section{十一 电子回旋加速器 (图 5 b)}

电了在加速过程中質量相对性增大很显著，国雄 亩期也就相应变長, 故不能用一般国旋办速器加速。 但假如我們特港地使电子·在每次加速后其回旋周期比 起电坊周期成整倍数增皮，則共振加速仍有可能維 持。这就要求行次得到的能量很火（和电子靜止能 量—- $510 \mathrm{Ker}$ - 一相近)，而且电坊周期要选擇的很 短。此时用普遄波長为“米”單位的商频本已不合肞， 而必須应用波長为“區米”治團的微波电坊了。这加逃 
器一般为几百万电子伏特。磁强不能取得很高，一般 只有一千奥斯式以下, 否则要求电源共振頻率更高, 受微波技术的限制。故能量不能做得很滈, 否则磁鉄 將很㢈大，不經济。

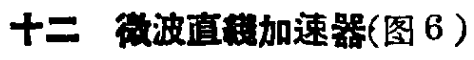

分为兩种基本类型。

a. 质手束

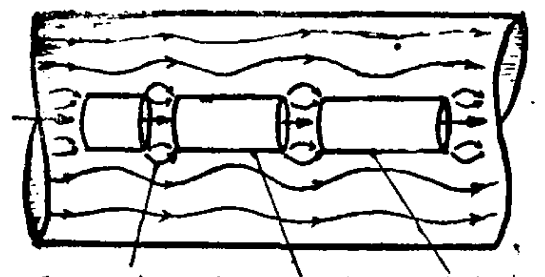

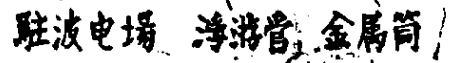

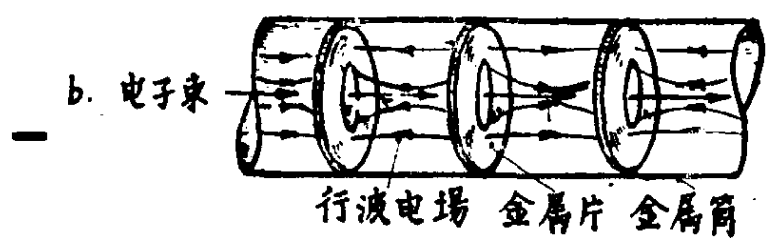

图 6

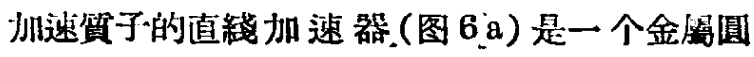
注，其軸中央故上很多金屬管作为加速电极，將一个 固定頻率的铔波发射到简內, 就在其中形成胿波电 㘯，集中在电极的縫間。質子自一端入射后，沿着軸 䋐就可以得到加速，电㘯大小是在随时間变化的，我們 可以事前把加速管的長度設棓好，使只作电㘯最大时， 贺子通过加速縫而获得能量, 而当电㘯縮小甚至变为 傎做的时候, 摆它們躬到管中去运动。这种加速器目 新最大的設訃能量为 $10^{3} \mathrm{Mev}(1 \mathrm{Bev})$, 总長为几百米。

电子直加速器(图六 b) 的原理有些不同, 金屬 结筒中炏的金屬圆片是有圆孔的，发射进去的是行波 电㘯。电子射入后, 基本上接近光速, 跟着电波一起

- 往前走，这样就可以沿途都受到电坋加速。金屬片唄 孔大小不一样, 是为了控制电波行进速度使和电子速 度保持一致。

这种加速器可以把电子加速到 $10^{3} \mathrm{Mev}$ (1Bev) 以 上的能星級。
直䋐加速器有䇢多优点：(1) 首先是它省却了一

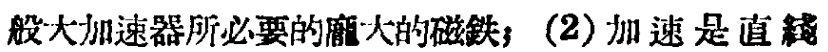
方问的, 輻射損失小, 能量提高不受其限徘; (3) 加 速自始至終直綫进行, 引出很方便, 粒小流損 失山 小，粒子“流强度甚至可以达几百毫安， (4) 要提高能 量可随时增加長度和高頻功率, 原理上还找不H限制 这种加速器能量提高的因素, 看来將来完全有可能取 代一般圓形軌道式的加速器, 很有发展前途。建造这 类加速器需要强功率的高频电源和高度的微波技术。

\section{十三 蕈東語}

当前放在加速器事策面前有雨个尖端任务。一是 提高粒于流的强度, 一是提高办速器的能星。这一切 都是为了进一步探索微观世界, 認識基本粒子的性 質，掌握其冈在規律，利用它来为人类服务。

对待前一項任务, 我们可以設法提高粒子源发射 强度, 尔用强聚焦原理, 或从改善加速器其他方面的 性能着手。对后一貣任务, 科学家們正在探絜新的加 速途徑。例如, 用一組被加速了的粒子流, 靠它們的 內电磁㘯力作用加速另一束粒子“流, 或用兩組被加速 的离子“流对碰, 也可利抙契林可夫效应所产生的輻射 㘯来加速等等。这些都还不够成熟, 有待进一步研 究。按估計, 用这些新方法可以把粒子能量 提高到 $10^{6} \mathrm{Mev}\left(10^{3} \mathrm{Bev}\right)$ 的水平。

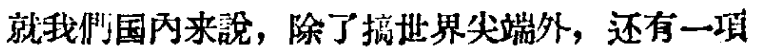
重要任务是普及原子能应用。当然, 这就要求发动垔 众来建造版速器, 要求我狮本着党所提出的“普及和 提高相結合”、“全面和重点相絬合”、“等家和基众相 絬合”、“土洋相結合”的方針, 努力把工作做好, 出 色地完成这項任务。

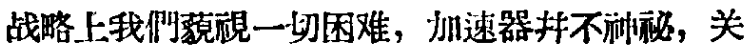
踺任于能否正确地执行党的方針，充分地发动基众。 但是在战术上, 我們却要仔細、謹㥜。如喆建什么样 的加速器, 选擇多大的能量, 干什么用, 要有怎样的 技术条件，林难有那些，如何去克服等等，都得识重 考虑。 